\title{
SOME COMMENTS ON FATIGUE LIFE TESTS OF AIRCRAFT CABLE CONTROL SYSTEMS
}

\author{
Józef Brzęczek • ORCID: 0000-0002-2431-9142 \\ Department of Components Manufacturing and Production Organization, \\ Faculty of Mechanics and Technology, Rzeszow University of Technology, \\ Kwiatkowskiego 4, 37-450 Stalowa Wola, Poland \\ j.brzeczek@prz.edu.pl
}

\begin{abstract}
Cable control systems are widely used in aircraft and gliders. This paper deals with the problem of collecting real loads acting cable control systems and cable tests preparation (load spectrum) and performance. The author proposes a method for defining real loads acting on control systems, preparing and carrying out fatigue tests of cables revealing symptoms of fretting. The fatigue tests results can be used to predict service life, to plan and prepare periodic and details inspections. This method could be used to increase service life of aircraft control cables and could help to replace the commonly used Time-Based Maintenance (TBM) strategy with the Damage Tolerance (DT).
\end{abstract}

Keywords: aircraft's cable control systems, cable service life, cable fatigue tests Article Category: Research Article

\section{INTRODUCTION}

Light airplanes will continue to be controlled with cable systems due to high mass and costs of electrical and hydraulic systems. The magnitudes of the forces transmitted by the cables result from the need to ensure the stability and controllability of the plane. The control is realized by the deflection (mostly of angles) of control surfaces in flight, correlated with the linear and angular displacements of elements of control systems (Fig. 1). The loads acting on control systems of the aircraft are complex and random (Fig. 9), and consist of the periodically variable, non-periodic and determined components, but they are always positive during any phase of an aircraft's operation [2]. The service life of control system cables is assessed according to the Time-Based Maintenance strategy or based on the visible signs of wear, i.e. wire breakage or traces of corrosion. The sources of plane control system loads are: 
- ground traffic loads (taxing, take-off and landing);

- loads due to atmospheric turbulence and vibrations caused by the air flow around the airframe and the power units;

- determined and undetermined loads during aviation missions:

- climb and descent;

- flight to the place of the task and arrival to the place of landing;

- maneuvers related to the accomplishing an aviation mission task.

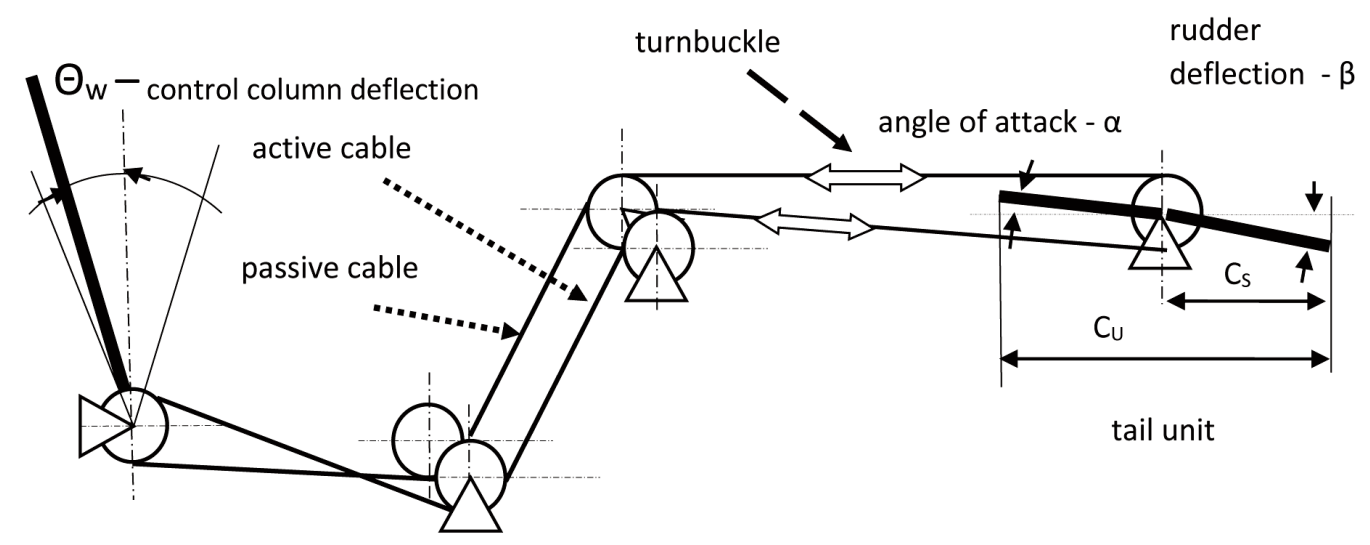

Fig. 1. The plane cable control system.

Load spectra are related to the intended use of the aircraft and its operation profile. From the point of view of applying loads to control systems, load spectra can be divided into:

- controlled loads (dependent on the pilots and their training, but determined by the intended use of the aircraft its and operation profile), and result from the tasks accomplished;

- controlled loads resulting from the pilot's or autopilot's response to disturbances in the flight trajectory (e.g. after a gust, engine asymmetry, etc.);

- environmental loads (depending on the condition of the atmosphere, the load on the power unit and the condition of the runway);

- aircraft characteristics (CG mass and position, aerodynamic characteristics, power unit characteristics, stiffness and deformations of the loaded airframe structure [1]).

The real values of the loads acting on control system elements during the flight mission (Fig. 2) are the result of the coincidence of operational load spectrum resulting from the exploitation profile. The stability and controllability requirements are met through the deflections of the control surfaces as well as the deflections and displacements of the related units and parts of the control systems and associated forces and moments. Collecting real loads acting on cable control systems is complex and difficult task. When measuring the random real forces of cable tension (Fig. 9), with a strain gauge attached to the turnbuckle, it is necessary to correlate the force value with the critical (largest) angular deformation of the cable in the control system pulley (1). Cable loads 
in connection with deformations on the pulleys and slides cause a complex state of stress in the cable strands and wires [3]:

- variable tension loads (always positive) [2], (2);

- variable bending loads (pulley or slide systems) (3);

- variable torsional loads (related to the cable structure) (4);

- pressure between the rope and the groove of the rope pulleys and the pressure between the cable strands and wires of the cable (5).

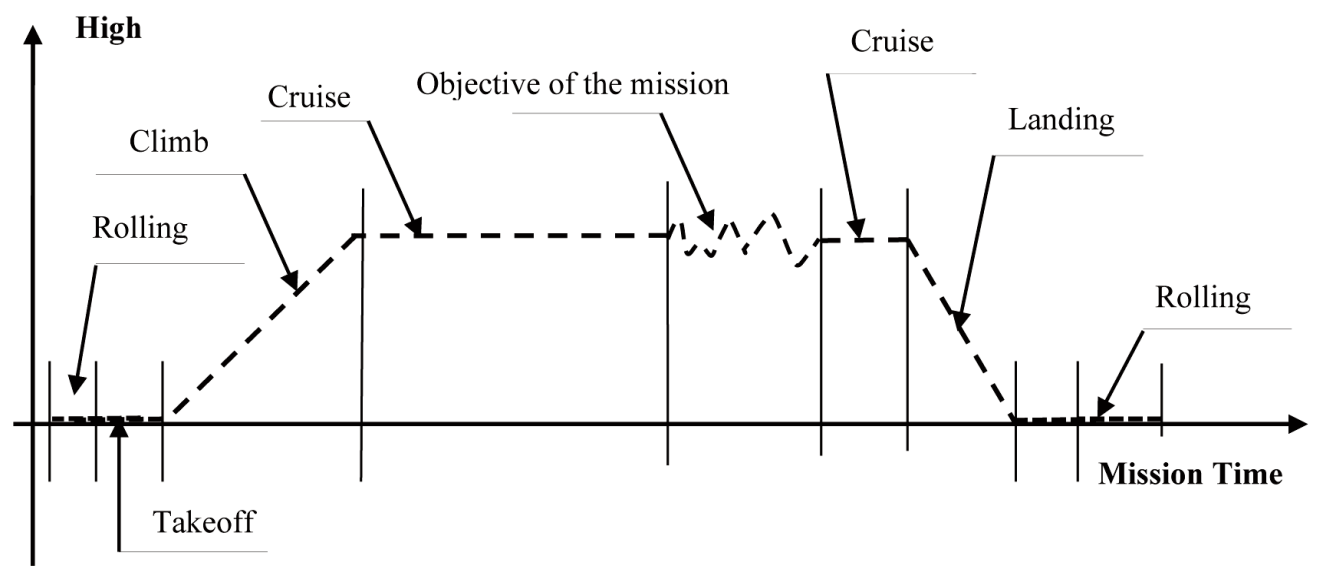

Fig. 2. A typical course of an air mission profile.

Due to the requirement, the cables must have a positive value for each extreme load [2], hence the need to introduce a preload tension of cables [1].

\section{DETERMINING THE SIZE AND VARIABILITY OF THE FORCES LOADING THE LINES}

Modeling of the tension forces in cables of the control system is represented by the formulas:

$$
\begin{aligned}
& P(\alpha, \beta, v, t)=P_{w}+k C_{M Z}(\alpha, \beta, v, t) \\
& P_{w}=P_{N}(t)+P_{M}
\end{aligned}
$$

where:

$P(t, \alpha, \beta, v)-$ total force in the active cables as a function of flight parameters, of a random character depending on the flight phase, Fig. 9;

$P_{W} \quad-$ total cable pre-tension force ensuring positive tension of the passive cable under extreme load conditions;

$P_{N} \quad-$ preload tension in the control system that guarantees a positive force value;

$P_{M} \quad-$ variable force $f(t, \alpha, \beta, v)$ due to deflections and accelerations occurring during flight and friction of the control system; 

$\alpha \quad-$ angle of attack Fig. 1;
$v \quad-$ flight speed;
$k-$ coefficient of calculation of the cable tension forces as a function of the deflection of the control surface $\beta$ Fig. 1;
$t \quad-$ ambient temperature;
$C_{M Z} \quad-$ hinge moment coefficient $f(t, \alpha, \beta, v)$ Fig. 3 or (6).

Modeling of bending stresses $\sigma_{g}$ for the most loaded cable wires [3] is presented by the formulas (3):

$$
\sigma_{g}=\frac{E_{L} d_{Z}}{D}
$$

$\begin{array}{ll}\sigma_{g} & - \text { bending stress; } \\ d_{Z} & - \text { diameter of the wires of the outer strands of the cable; } \\ E_{L} & - \text { cable elasticity modulus; } \\ D & - \text { diameter of the bottom of the pulley. }\end{array}$

Modeling of torsion stresses (4);

$M_{s}=k_{o} P$

$k_{O} \quad-$ conventional rotation radius of the cable;

$P \quad-$ tensile force in the cable (1).

Pressure modeling (5):

$$
p_{o}=\frac{2 P}{D d}
$$

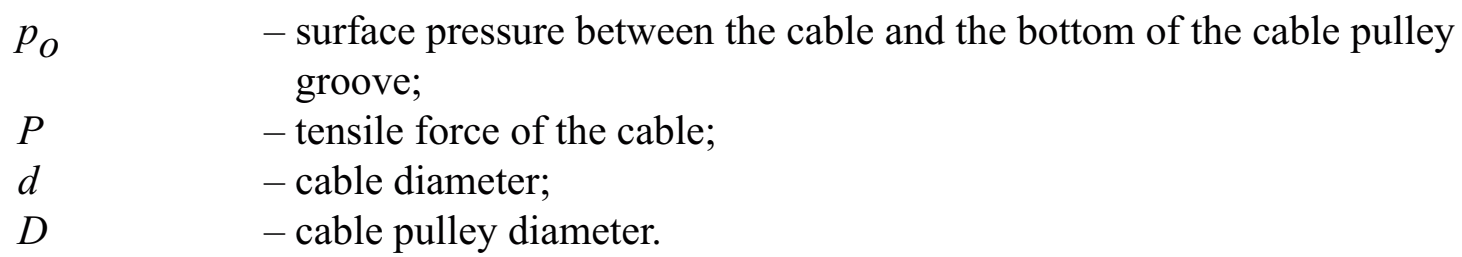

Preparing the real spectrum of the cable tension loads during a plane's operation can be carried out in the following ways:

a) gauge measurement of the tensile load and correlation with the angles of deflection;

b) measurement of angle deflections and correlation with hinge moments of control surfaces $[4,5]$

c) measurement of forces determined by flight parameters and determination of the $C_{M Z}=f(\alpha, \beta)$ characteristics, commonly it is linear form [5]. 
The value of the coefficients of the hinge moments of the control surfaces determined by the data obtained from tunnel tests [6] is given by the formula (6):

$$
C_{M Z}(\mathrm{Re}, \mathrm{M}, \mathrm{K})=b_{1} \alpha+b_{2} \beta+b_{0}
$$

where:

$b_{1}=\frac{\partial C_{M Z}}{\partial \alpha}$

$b_{2}=\frac{\partial C_{M Z}}{\partial \beta}$

$b_{0} \quad-$ coefficient related to the shape of the tail profile.

$$
K=\frac{C_{S}}{C_{U}}
$$

where:

$C_{S} \quad-$ rudder chord;

$C_{U} \quad-$ chord of the control surface unit;

Re, M $\quad-$ Reynolds and Mach numbers.

The theoretical determination of the values of the hinge coefficients $C_{M Z}=f(\alpha, \beta)$ is very difficult, so it is used only for preliminary analyzes. This is due to the influence of many additional factors that are difficult to define theoretically: the control unit shape, the shape of the nose and the trailing edge of the profile, the gap between the fin and the rudder, the nature of the flow, e.g. disturbance of the propeller and so on. Therefore, reliable data should be obtained through investigations either in the wind tunnel or in flight. This paper presents two solutions that could be used to determine the $C_{M Z}$ coefficient:

- directly, by using the $C_{M Z}=f(\alpha, \beta)$ chart for specific aviation profiles with appropriate values of $\mathrm{K}, \mathrm{Re}, \mathrm{M}$ (Fig. 3);

- analytically, with method based on the specific wind tunnel test that uses coefficients $b_{1}, b_{2}, b_{0}$ for specific K, Re, M (Fig. 4, Fig. 2).

In both solutions proposed, it can be seen that the linear relationships of the coefficients concern the usable fin angles of attack $\alpha$ and the deflection angles of the control surfaces $\beta$ for the air flow scope $M=(0-0.7)$, which meets specifications CS 23.321 [2]. Due to the occurrence of near-critical and over-critical states of flight, the proposed ideas cannot be applied to aerobatic airplanes. 


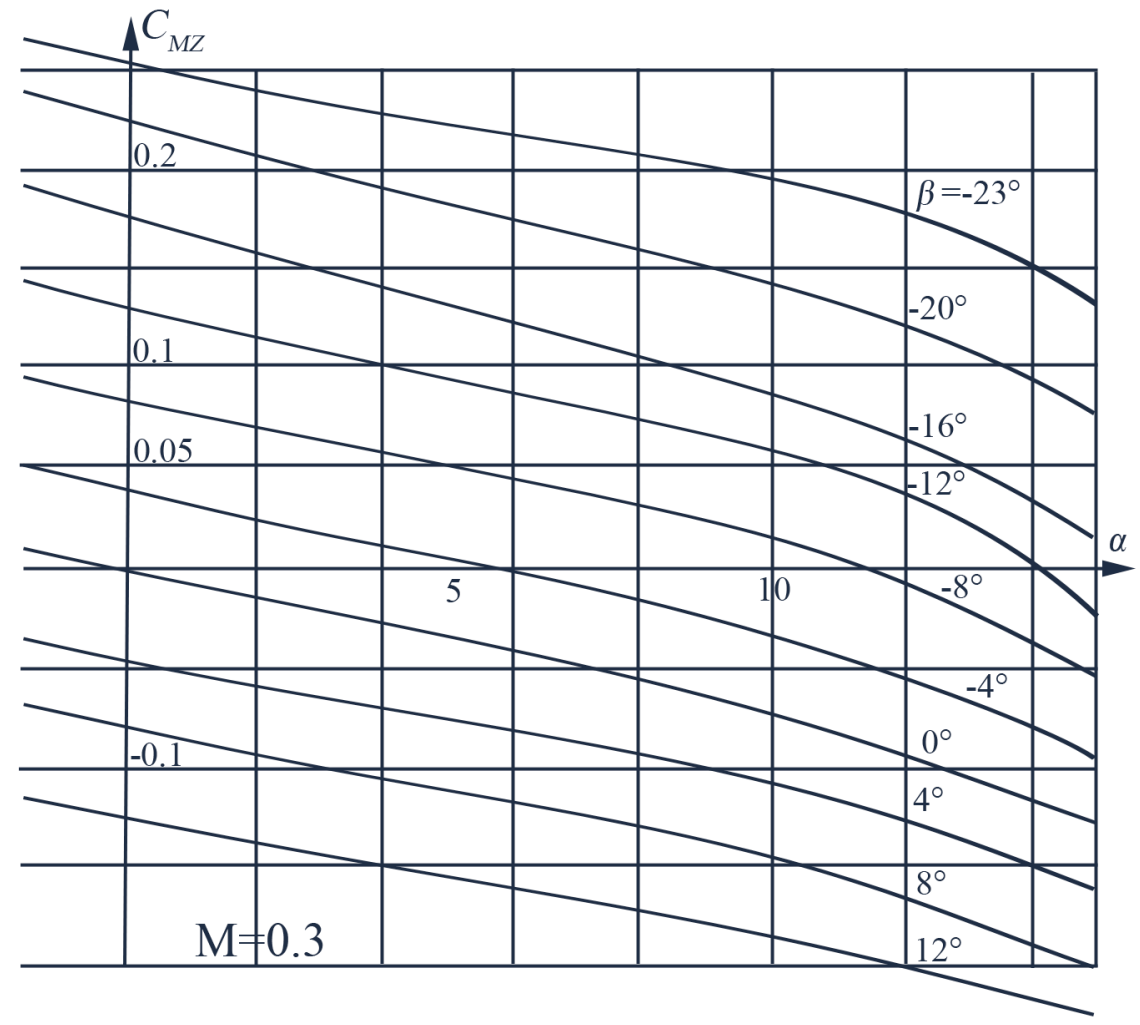

Fig. 3. An example of the $C_{M Z}=f(\alpha, \beta)$ for specific values of $\mathrm{K}=0.25$, $\operatorname{Re}=1.4910^{6}$, and $M=0.3[5]$.

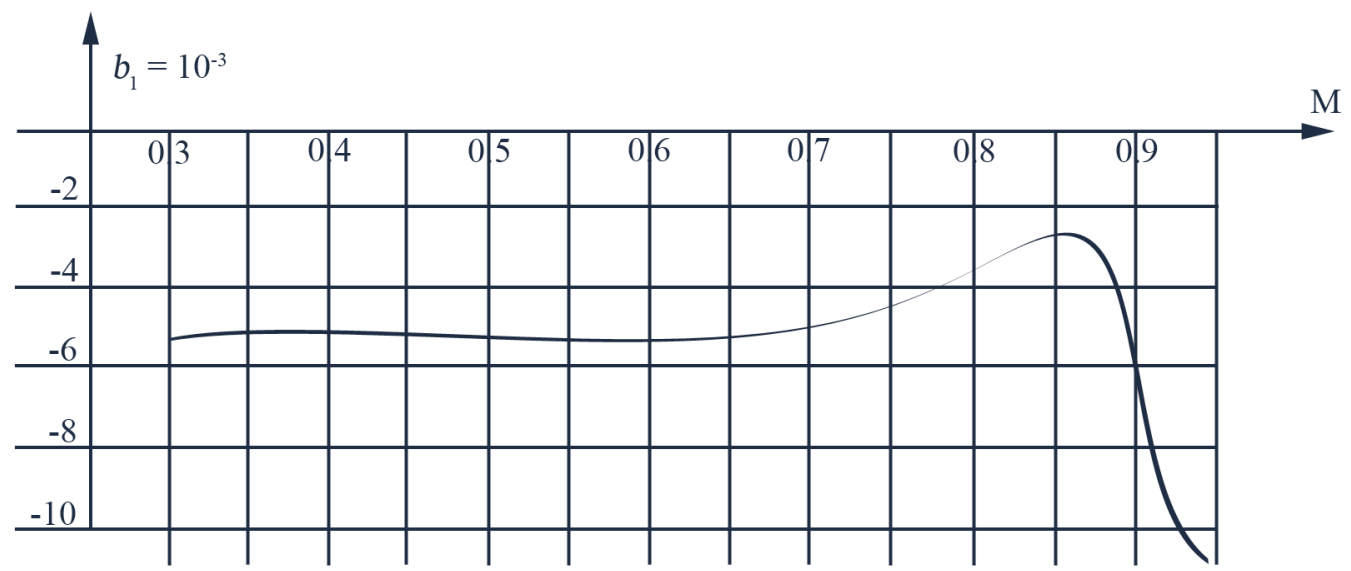

Fig. 4. An example of $b_{1}=f(\mathrm{M})$ for the value $\mathrm{K}=0.25$ [5].

Tension loads of the passive and active cables of the plane control system should be additionally corrected by the friction forces of the systems [1]. The proposed solution based on real deflections of the rudder obtained from flight tests is both easier and cheaper. The values of the deflections $\beta$ are additionally correlated with the angles of attack $\alpha$, which allows for a complete determination of the operating spectrum. 
Assuming the linearity of the $C_{M Z}=f(\alpha, \beta, v)$, it is possible to apply another solution in the form of real measurements of the real forces on the flying controls in set phases of flight with corrective theoretical calculations based on the results of controls forces measuring in selected flight phases.

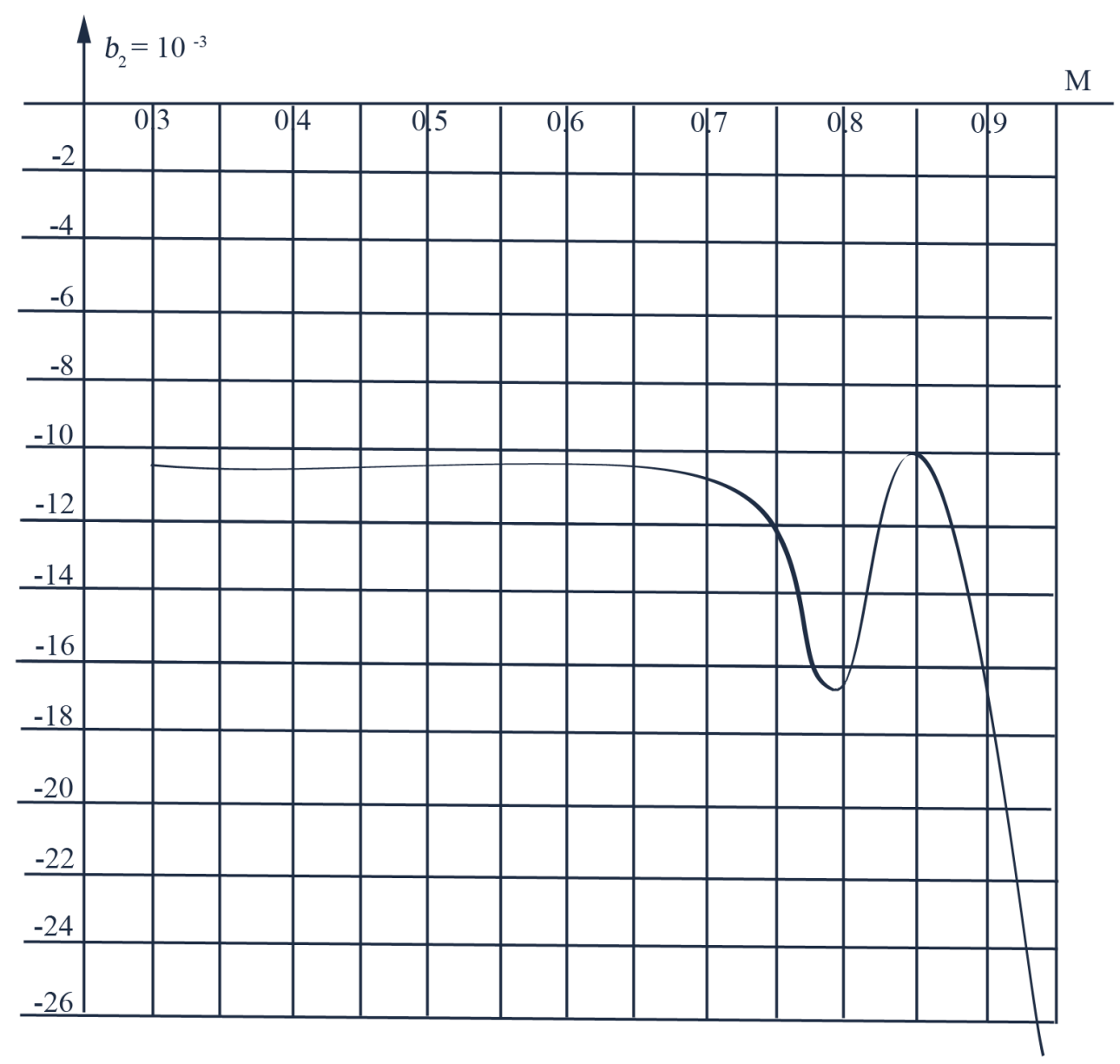

Fig. 5. An example of $b_{2}=f(\mathrm{M})$ for the value $\mathrm{K}=0.25$ [5].

\section{FATIGUE TESTS OF CABLE CONTROL SYSTEMS}

Currently, the method of determined and symmetrical loads is used in analyzes and fatigue tests of plane control systems, modeled on the tests of elevators ropes. Such studies models are correct to operational loads of cable transport systems: cranes, lifts, horizontal cable transport [3]. The PN-91/M-80235 standard requires the implementation of two-sided bends with constant tension load of the tested ropes. In the case of testing mining transport ropes, the rope rotation mechanism and vibrations related to the lifted tension load are additionally introduced [3]. This approach results based on the standard method of determining the fatigue life of metal parts defined on the Wohler curve, and the fatigue tests are carried out in the positions presented in Fig. 4, 5. The basic differences related to the operation of elevator ropes and aircraft cable control systems are tension loads of stochastic nature that occur in the same area of the cable. In addition, 
as emphasized in this paper, the magnitude of the loads and cable deformation is correlated with the amount of deflection and displacement of control system components.

Loads and their operational spectrum related to a specific type of airplane and its intended use, also allow defining, a critical point on the cable which should be used in planning periodic system control. Present research of aviation control cable is based on the tests of cable bends with tension load [6], with the number of broken wires recorded as a function of the number of bends without registering the cable elongation.

For GA airplanes and sailplanes control systems, this research method is too conservative and can be used as a comparative date. Presented in Fig. 6 stand is similar to the stand described in [3] and could be used to obtain results which only partially reflect the changes in tension loads as a function of the deflection of the control surface (Fig. 1). The applied loads are not correlated with the values of deflections, displacements or bends. For hoisting ropes, this method of rope durability assessment is acceptable and provides basis data for forecasting the fatigue life of the ropes.

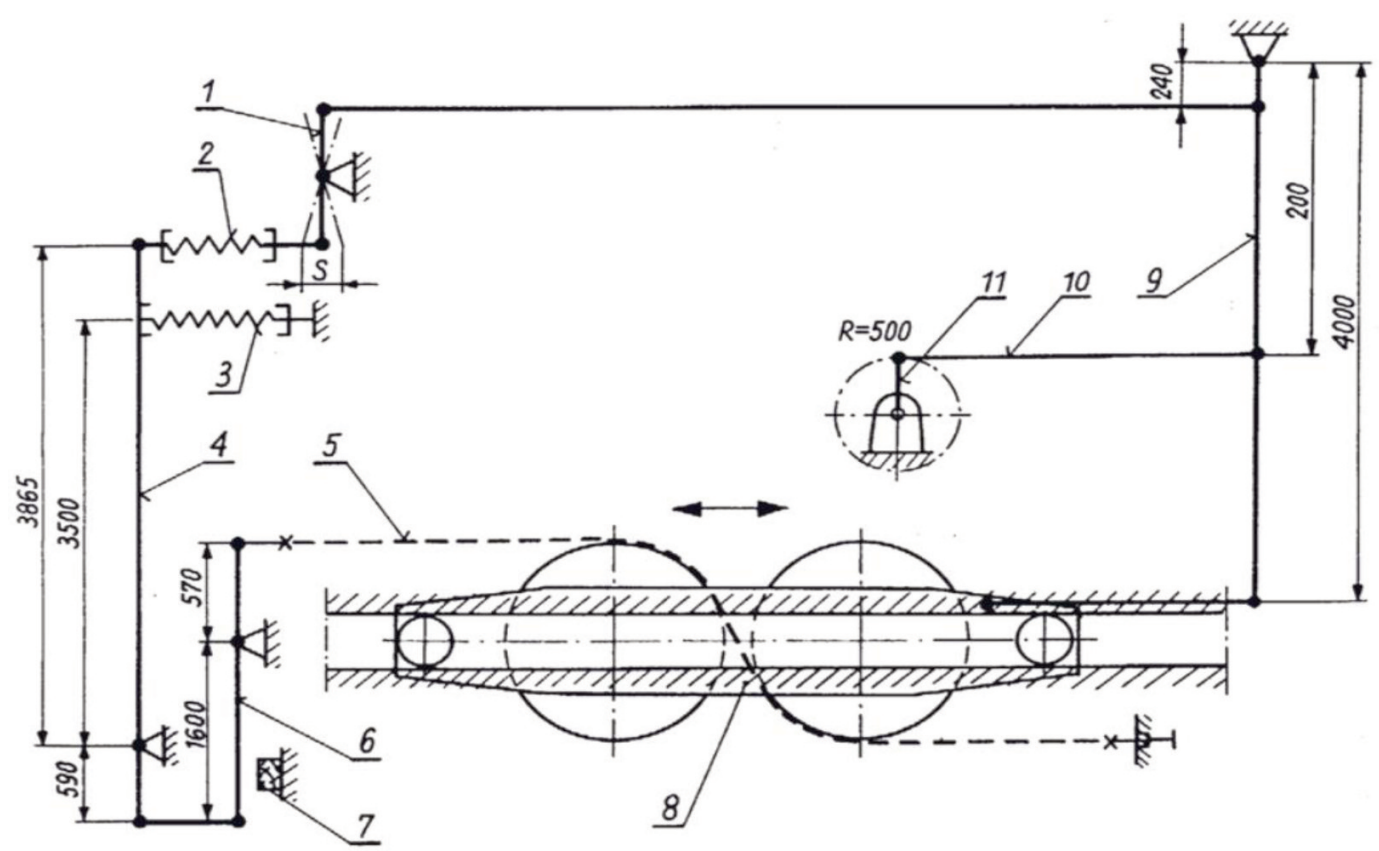

Fig. 6. Kinematic diagram of the P4-GIG-2 fatigue machine [3].

Determined tension load pulsation 2, 3 - tension spring.

\section{ASSESSMENT OF FATIGUE LIFE OF AIRPLANE CONTROL SYSTEM CABLES}

The test stand presented in [6] and the results obtained are not related to the actual loads and don't meet the conditions of actual increases in tensile force in the cable (Fig. 8), so the fatigue life assessment is reduced to counting the number of broken wires as a function of cable bending. The test results in the form of the number of broken wires of the tested cable at a bends by an angle of $+/-90^{\circ}$ do not permit for prediction of the actual fatigue life of the cable [3]. 
The tests carried out in such a way from the immediate strength test give a result of a comparative nature and constitute the basis for the acceptance of the cable batch, and not for the evaluation of operating durability. The evaluation by the rate of crack growth and the cable residual strength after the end of the fatigue test doesn't justify for transferring the results to the real operating conditions. The regulations [2] require visual inspection of cables during operation, e.g. during inspections after 50 hours of flight. In practice, the decision whether to replace a control cable is made if traces of corrosion occur or a wire break in the cable. The method described above is considered as too conservative.

A measure of the symptoms of wear of the control cable is the decrease in initial tension caused by the elongation and reduction of cable diameter. The wear of an individual wire of the cable is of fatigue and tribological type. The course of the curve, lengthening of the operated cable or rope is similar to the tribological curve and, in accordance with [3], can be well described with a third-degree polynomial (10):

$$
\varepsilon=a_{0}+a_{1} P+a_{2} P^{3}+a_{3} P^{3}
$$

$$
\begin{array}{ll}
\varepsilon & - \text { limit elongation of the cable or rope; } \\
P & - \text { tensile load } P(\alpha, \beta, v, t) \text { according to (1). }
\end{array}
$$

The assessment of the limit elongation of the cable can be determined by the controlling its tension [1]. Based on the results of measuring the cable elongation, its replacement date can be predicted [3].

It remains to be solved how the flight time after the first wire breakage will ensure the safe operation of the aircraft. It should be possible to resolve this issue after analyzing the course of the curve defined by the formula (10).

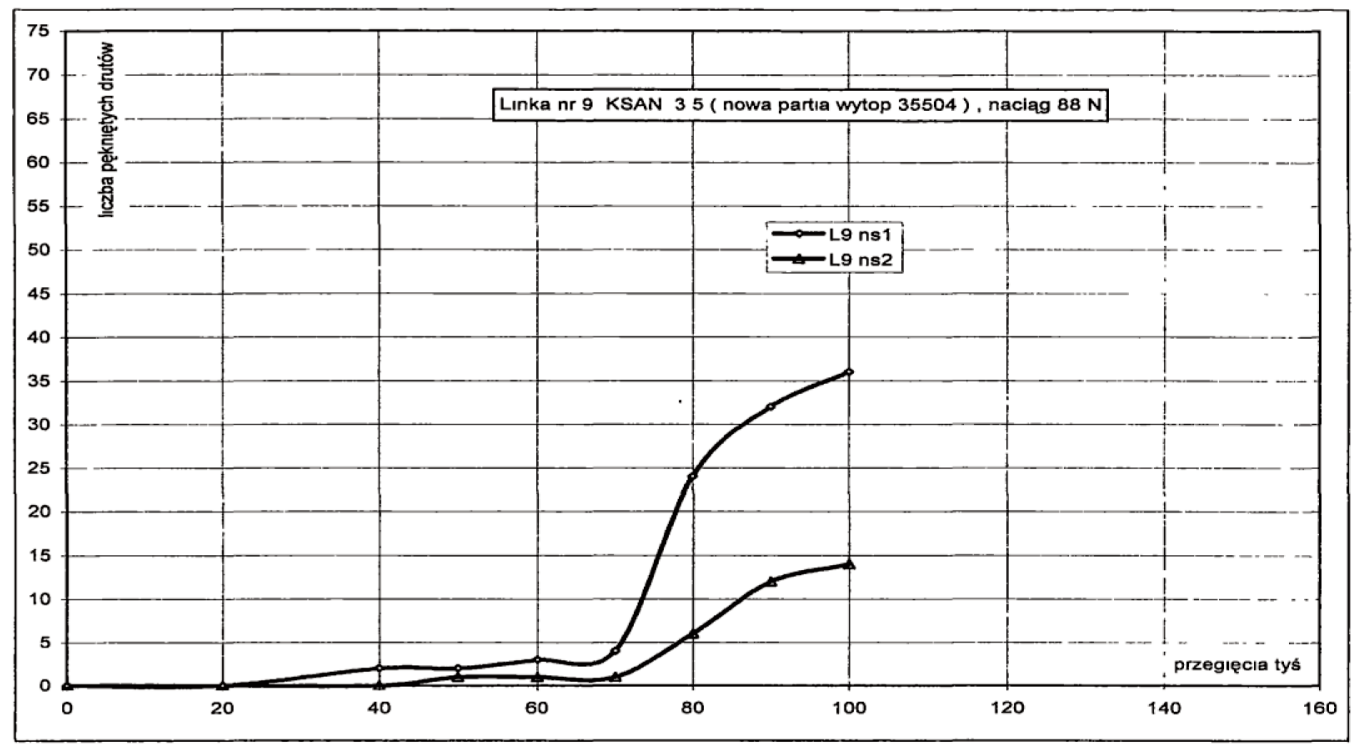

Fig. 8. The results of the KSAN cable tests diam. $3.5 \mathrm{~mm}$ up to $100.000+/-90^{\circ}$ bends [6]. 


\section{A RESEARCH METHOD BASED ON REAL LOADS}

The paper proposes a solution based on the use of measurements of the actual deflections of the control surfaces necessary to meet the stability and controllability during an aircraft's operation. Measurement of stochastic deflections of the surface is an indirect method of determining loads in active and passive cables of control systems (Fig. 1). Modeling the test spectrum for tests with a better approximation of the real loads [5], in conjunction with correlated cable displacements and deflections, with the operating elongation of the cable collecting will also allow the determination of cable fretting and fatigue life. The tests results as function of flight hours of a given type of aircraft (loads based on its operation profile) should be performed on the critical pulley of the system, i.e. on the greatest bending. Modeling and conducting fatigue tests of the cable should be based on the real distribution of loads (Fig. 9), obtained from the operational spectrum with additional measurement of the cable elongation and collecting the broken wires as well. Based on the results of fatigue tests described above, the maximum real geometric deformation can be determined by:

1) curve of elongation versus number of flight hours;

2) the curve of the number of broken wires as a function of the number of flight hours.

Based on the data presented above, the polynomial (6) can be used to determine the fatigue life and to forecast the cable's target fatigue life. Due to the implementation of the initial tension [1], the actual length of the control cable should be considered in the preparation and execution of the test. The aircraft control cables are relatively short, approx. $20 \mathrm{~m}$ long, additionally limited by the possibility of measuring elongation, hence the measurement should be carried out based on the operational tension control [1].

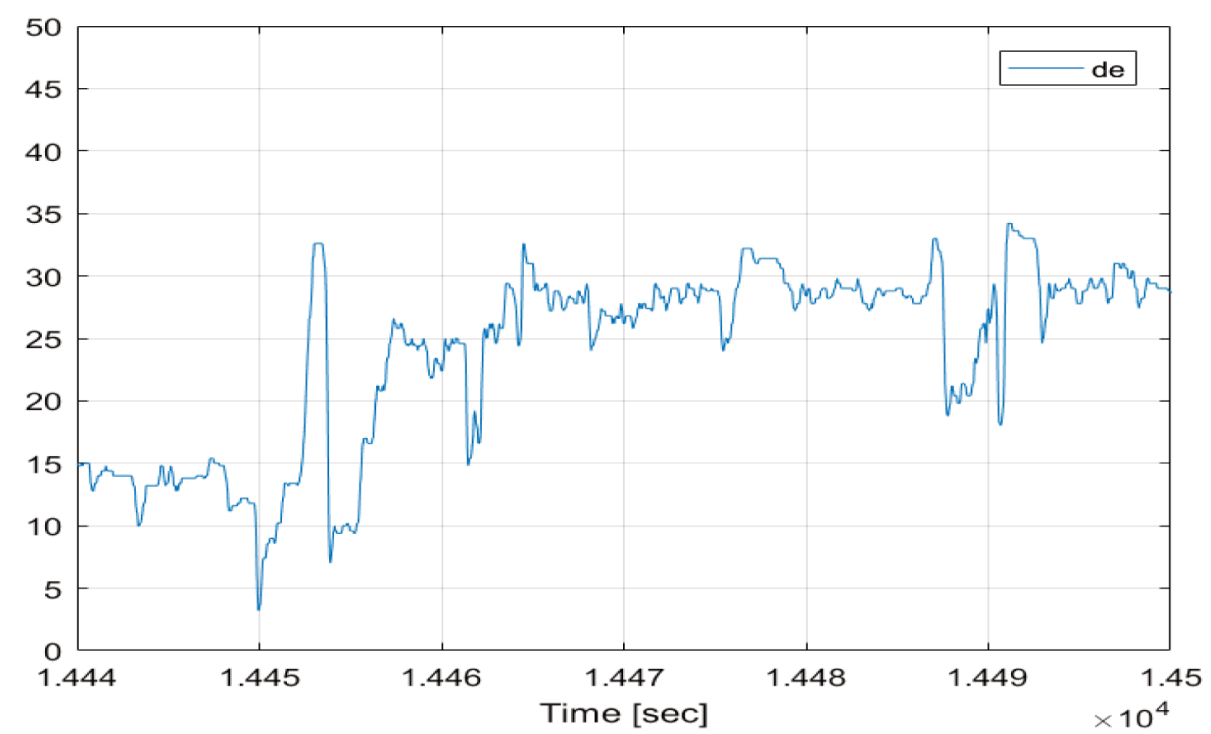

Fig. 9. Elevator deflections $\beta_{h}$ during 6 sec. in the cruise phase of aircraft's flight [4]. 


\section{CONCLUSIONS}

The presented method of preparing and carrying out fatigue tests of airline control cable is based on the real loads and deformations of the cable with their random values of forces and deformations. The longitudinal load on the cables with the associated complex loads of individual wires of the cable, in the presented proposal, are disturbed by determination of the real values of the hinge moment (four methods have been defined) and the influence of deformation of the aircraft structure and the influence of mass effects as well. The solutions proposed are based either on flight measurements or on laboratory wind tunnel profiles tests. The advantage of the presented solutions is the availability of data related to the real surface deflections of control systems. The major drawback to this method is that it requires controlling the cable tension with the appropriate measurement accuracy, which according to [1] is a complex task. The results of the measurement of the line elongation as a function of flight hours give reliable information on the service life of the cable control system, inspection, forecasting fatigue life and decisions concerning cable replacement.

The presented method of determining the load spectrum of the cable control system is not suitable for aerobatic airplanes. Even if it were possible to determine $C_{M Z}$ in a laboratory for values around and above $\alpha_{k r}$ with additionally extreme values of the rudder deflections $\beta$, then, with the proposed method, would not be possible to determine the magnitude of the forces at e.g. slips or autorotative maneuvers. For airplanes and aerobatic gliders, the only reliable method of determining the real operational loads of control systems should be strain gauge measurements.

\section{REFERENCES}

[1] Brzęczek, J. (2019). Examination of Aircraft's cable Control Systems Tension. Advances in Science and Technology Research Journal, 13(2), 65-71.

[2] Certification specifications for CS-23 Normal, Performance, Aerobatic and Local Transport Aircraft, November 14, 2003 and related AMC and FTG.

[3] Hankus, Ł. (2014). Longitudinal strains of hoisting ropes under conditions of complex cyclically changeable loads. (In Polish: Wzdłużne odkształcenia lin wyciągowych w warunkach złożonych obciążeń cyklicznie zmiennych). Przegląd Górniczy, No. 5, 101.

[4] Rzeszow University of Technology. Flight tests of the MP-02 Czajka aircraft Rzeszów 2019 - unpublished.

[5] Krzysiak, A. (1983). Experimental studies of the hinge torque in terms of sub and sonic speeds. (In Polish: Eksperymentalne badania momentu zawiasowego w zakresie pod i przydźwiękowych prędkości), Transactions of the Institute of Aviation, No. 94, 3-20.

[6] Kubryn, M., Gruszecki, H., Pieróg, L., Chodur, J., Pietruszka, J. and Brzęczek, J. (2018). Fatigue life of cables in aircraft flight control systems. Fatigue of Aircraft Structures, 2018(10), 53-62. 